\title{
What's new in the management of chronic lymphocytic leukemia? 2008 ASH Review (New York Medical College, January 31, 2009) Kami J Maddocks and Thomas S Lin*
}

\author{
Address: The Ohio State University, Division of Hematology-Oncology, 320 West 10th Avenue, Columbus, OH 43210, USA \\ Email: Thomas S Lin* - thomas.lin@osumc.edu \\ * Corresponding author
}

from Current trends in leukemia, lymphoma and myeloma

White Plains, NY, USA. 31 January 2009

Published: 26 June 2009

Journal of Hematology \& Oncology 2009, 2(SuppI I):II doi:I0.II86/I756-8722-2-SI-II

This article is available from: http://www.jhoonline.org/content/2/SI/II

(c) 2009 Maddocks and Lin; licensee BioMed Central Ltd.

The 2008 ASH Annual Meeting featured several important abstracts highlighting advances in the treatment of chronic lymphocytic leukemia (CLL).

Abstract 43 [1] retrospectively compared results of a phase II study of pentostatin and rituximab (PR) to previously published results using pentostatin, cyclophosphamide and rituximab (PCR) [2]. The pentostatin dose was increased to $4 \mathrm{mg} / \mathrm{m}^{2}$ in the PR regimen, but demographics of patients in both studies were similar [1]. Overall response rate (OR) and complete response (CR) rates were similar for PR $(79 \%, 30 \%)$ and PCR $(91 \%, 41 \%)$, but median progression free survival (PFS) was significantly shorter for PR (12 months vs. 31 months) [1]. These results supported previous findings that the addition of cyclophosphamide to fludarabine improves OR, CR and PFS [3-5].

Abstract 325 presented results of the German CLL Study Group (GCLLSG) CLL8 study randomizing 817 previously untreated patients to fludarabine and cyclophosphamide (FC) or fludarabine, cyclophosphamide and rituximab (FCR) [6]. OR, CR and median PFS favored FCR (93\%, 45\%, 43 months) over FC (85\%, 23\%, 32 months), although 2-year overall survival (OS) was similar (91\% vs. 88\%). Abstract 326 demonstrated that median PFS depended upon the ability to eradicate minimal residual disease (MRD) in the peripheral blood, with PFS increasing from 15 months $\left(\mathrm{MRD} \geq 10^{-2}\right)$ to 34 months $\left(10^{-4} \geq\right.$ $M R D>10^{-2}$ ) to not reached (MRD $<10^{-4}$ ) with increasing eradication of MRD [7]. Furthermore, $67 \%$ of patients receiving FCR achieved MRD $<10^{-4}$, compared to only $34 \%$ of FC patients, thus accounting for the improved PFS with FCR.

Abstract 327 randomized 184 patients (80\% previously untreated, 20\% relapsed) to PCR or FCR, using the MSKCC PCR regimen (pentostatin dose $4 \mathrm{mg} / \mathrm{m}^{2}$ ) and the Johns Hopkins FCR regimen (fludarabine $20 \mathrm{mg} / \mathrm{m}^{2}$ days $1-5$, cyclophosphamide $600 \mathrm{mg} / \mathrm{m}^{2}$ day 1 ). The primary endpoint, incidence of grade 3-4 infections, was similar for PCR (34\%) and FCR (31\%). Only 50\% of patients in both arms completed therapy, resulting in surprisingly low OR and CR rates for PCR $(45 \%, 7 \%)$ and FCR (58\%, $17 \%)$. The trial was stopped early, so there were no statistically significant differences between the two arms, and no PFS data was presented. Nonetheless, abstract 327 indicated that results from academic centers may not necessarily be reproducible in the community [8].

Abstract 2095 updated results of a phase II study of cyclophosphamide, fludarabine, alemtuzumab and rituximab (CFAR) in 48 previously untreated patients with high-risk features [9]. OR and CR were $94 \%$ and $69 \%$, respectively, with OR $77 \%$ and CR $54 \%$ in 13 patients with del (17p13). Grade 3-4 neutropenia and thrombocytopenia were observed in $71 \%$ and $42 \%$ of patients, respectively, and $6 \%$ and $27 \%$ of patients developed major and minor infections, respectively. 
Abstract 2091 updated results of a phase III study randomizing 319 previously untreated patients to chlorambucil or bendamustine [10]. OR, CR and median PFS favored bendamustine $(67 \%, 32 \%, 21.5$ months) over chlorambucil (30\%, 2\%, 8.3 months), although bendamustine caused greater hematologic toxicity $(40 \%$ vs. $19 \%$ ), especially grade $3-4$ neutropenia ( $23 \%$ vs. $9 \%$ ).

Two studies of lenalidomide in previously untreated patients were presented $[11,12]$. Abstract 44 summarized results of a phase I study in 25 Canadian patients [11]. Due to grade 5 sepsis and grade 3-4 tumor lysis, the dose was decreased from $25 \mathrm{mg}$ to $2.5 \mathrm{mg}$ and then escalated to $10 \mathrm{mg}$ daily for 21 days every 28 days. Toxicity included fatigue $(78 \%)$, tumor flare $(78 \%)$, rash $(48 \%)$ and grade 3-4 neutropenia (43\%). OR and CR were $65 \%$ and $0 \%$, respectively. Abstract 45 presented a study in 43 elderly patients age 65 or older [12]. Lenalidomide was given continuously, and 5-10 mg daily was the median delivered dose. Grade 3-4 myelosuppression and tumor flare were observed in $26 \%$ and $44 \%$ of patients, respectively. OR and CR were $54 \%$ and $0 \%$, respectively. While lenalidomide is clearly active in CLL, the absence of CR in previously untreated patients was disappointing.

Abstract 47 presented a phase II study giving high dose methylprednisolone $1000 \mathrm{mg} / \mathrm{m}^{2}$ day $1-3$ every four weeks and weekly rituximab (total dose $4500-6750 \mathrm{mg} /$ $\mathrm{m}^{2}$ ) to 28 patients [13]. OR and CR were $96 \%$ and $32 \%$, respectively. Patients were lesser splenomegaly and lower beta-2-microglobulin levels were more likely to respond.

In the relapsed setting, abstract 329 presented final results of the GCLLSG CLL2H study which administered subcutaneous alemtuzumab to 103 relapsed patients, many of whom had high-risk features [14]. Infusion toxicity was minimal, but grade 3-4 anemia (56\%), thrombocytopenia $(57 \%)$, anemia $(49 \%)$, cytomegalovirus reactivation $(8 \%)$ and non-CMV infection $(29 \%)$ were significant toxicities. Seventy-five patients died; $56 \%$ died of progressive CLL, and $31 \%$ died of infection. OR (34\%), CR (4\%) and median PFS (7.7 months) were similar to the results achieved by intravenous alemtuzumab in the pivotal CAM211 study [15].

Abstract 330 summarized a phase II GCLLSG trial administering bendamustine $70 \mathrm{mg} / \mathrm{m} 2$ on day $1-2$ and rituximab $500 \mathrm{mg} / \mathrm{m} 2$ on day 1 to 81 relapsed CLL patients [16]. OR and CR were $77 \%$ and $15 \%$, respectively. Twelve of 13 patients (92\%) with del (11q22), 4/9 patients (44\%) with del (17p13), and 29/39 patients (74\%) responded, indicating that bendamustine is active in highrisk relapsed CLL.
Abstract 46 presented combined phase I/II results of flavopiridol (alvocidib) in 116 relapsed patients, 70\% of whom were fludarabine-refractory [17]. OR in this highrisk population was 47\%. Furthermore, 19/39 del (17p13) patients (49\%), 28/47 del (11q22) patients $(60 \%)$ and $22 / 52$ complex karyotype patients (42\%) responded, demonstrating the activity of flavopiridol in poor-risk groups with limited therapeutic options. Fortyone of 85 patients (48\%) with bulky lymphadenopathy > $5 \mathrm{~cm}$ responded. Median PFS in responders was 10-12 months across all risk groups. A registration study is ongoing.

Finally, abstract 328 presented a pivotal phase II study of the fully humanized anti-CD20 antibody ofatumumab (HuMax-CD20) in relapsed patients refractory to both fludarabine and alemtuzumab (DR, $n=59)$ or with bulky lymphadenopathy refractory to fludarabine $(B F R, n=79$ ) [18]. OR, time to next therapy, and OS were similar for the DR (51\%, 9.0 months, 13.7 months) and BFR groups (44\%, 7.9 months, 15.4 months). These results have been submitted for FDA approval.

\section{Competing interests}

The authors declare that they have no competing interests.

\section{Acknowledgements}

This article has been published as part of Journal of Hematology \& Oncology Volume 2 Supplement I, 2009: Current trends in leukemia, lymphoma, myeloma and ITP: updates and highlights from ASH 2008. The full contents of the supplement are available online at http://www.jhoonline.org/supple ments/2/SI.

\section{References}

I. Kay NE, Wu W, Byrd JC, Kabat B, Jelinek DF, Zent CS, Call T, Lin T, Shanafelt T: Cyclophosphamide remains an important component of treatment in CLL patients receiving pentostatin and rituximab based chemoimmunotherapy. Blood 2008, I I 2:22.

2. Kay NE, Geyer SM, Call TG, Shanafelt TD, Zent CS, Jelinek DF, Tschumper RC, Bone ND, Dewald GW, Lin TS, et al.: Combination chemoimmunotherapy with pentostatin, cyclophosphamide, and rituximab shows significant clinical activity with low accompanying toxicity in previously untreated B chroinc lymphocytic leukemia. Blood 2007, 109:405-4I I.

3. Eichhorst BF, Busch R, Hopfinger G, Pasold R, Hensel M, Steinbrecher C, Siehl S, Jager U, Bergmann M, Stilgenbauer S, et al.: Fludarabine plus cyclophosphamide versus fludarabine alone in first-line therapy of younger patients with chronic lymphocytic leukemia. Blood 2006, I 07:885-89I.

4. Catovsky D, Richards S, Matutes E, Oscier D, Dyer MJ, Bezares RF, Pettitt AR, Hamblin T, Milligan DW, Child JA, et al.: Assessment of fludarabine plus cyclophosphamide for patients with chronic lymphocytic leukaemia (the LRF CLL4 Trial): A randomised controlled trial. Lancet 2007, 370:230-239.

5. Flinn IW, Neuberg DS, Grever MR, Dewald GW, Bennett JM, Paietta EM, Hussein MA, Appelbaum FR, Larson RA, Moore DF, et al.: Phase III trial of fludarabine plus cyclophosphamide compared with fludarabine for patients with previously untreated chronic lymphocytic leukemia: US Intergroup Trial E2997. J Clin Oncol 2007, 25:793-798.

6. Hallek M, Fingerle-Rowson G, Fink AM, Busch R, Mayer J, Hensel M, Hopfinger G, Hess G, von Gruenhagen U, Bergmann MA, et al:: Immunochemotherapy with fludarabine (F), cyclophosphamide (C), and rituximab (R) (FCR) versus fludarabine and 
cyclophosphamide (FC) improves response rates and progression-free survival (PFS) of previously untreated patients (pts) with advanced chronic lymphocytic leukemia (CLL). Blood 2008, I | 2: I 25.

7. Boettcher S, Fischer K, Stilgenbauer S, Busch R, Fingerle-Rowson G, Fink AM, Dohner H, Hallek M, Kneba M, Ritgen M: Quantitative MRD assessments predict progression free survival in CLL patients treated with fludarabine and cyclophosphamide with or without rituximab - a prospective analysis in 47 I patients from the randomized GCLLSG CLL8 trial. Blood 2008, I I 2:125-126.

8. Reynolds C, Di Bella N, Lyons RM, Hyman WJ, Lee GL, Richards DA, Robbins G], Vellek M, Boehm KA, Zhan F, et al:: Phase III trial of fludarabine, cyclophosphamide, and rituximab vs. pentostatin, cyclophosphamide, and rituximab in B-cell chronic lymphocytic leukemia. Blood 2008, I I 2: 126.

9. Wierda WG, O'Brien SM, Faderl SH, Ferrajoli A, Koller C, Estrov Z, Burger JA, Lerner S, Kantarjian HM, Keating MJ: CFAR, an active frontline regimen for high-risk patients with CLL, including those with del I7p. Blood 2008, I 1 2:729.

10. Knauf WU, Lissitchkov T, Aldaoud A, Liberati AM, Loscertales J, Herbrecht R, Juliusson G, Postner G, Gercheva L, Goranov S, et al.: Bendamustine versus chlorambucil as first-line treatment in $B$ cell chronic lymphocytic leukemia: An updated analysis from an international phase III study. Blood 2008, I I 2:728.

11. Chen C, Paul H, Xu W, Kukreti V, Trudel S, Wei E, Li ZH, Brandwein J, Pantoja M, Leung-Hagensteijn C: A phase II study of lenalidomide in previously untreated, symptomatic chronic lymphocytic leukemia (CLL). Blood 2008, I I 2:23.

12. Ferrajoli A, O'Brien S, Wierda W, Faderl S, Kornblau S, Yerrow K, Estrov Z, Kantarjian H, Keating M: Lenalidomide as initial treatment of elderly patients with chronic lymphocytic leukemia (CLL). Blood 2008, I I 2:23.

13. James DF, Castro JE, Sandoval-Sus JD, Jain S, Bole J, Rassenti L, Kipps TJ: Rituximab and high-dose methylprednisolone for the initial treatment of chronic lymphocytic leukemia is associated with promising clinical activity and minimal hematologic toxicity. Blood 2008, I I 2:24.

14. Stilgenbauer S, Zenz T, Winkler D, Buhler A, Groner S, Busch R, Hensel M, Duhrsen U, Finke J, Dreger P, et al.: Subcutaneous alemtuzumab (Campath) in fludarabine-refractory CLL: Final results of the CLL2H trial of the GCLLSG and comprehensive analysis of prognostic markers. Blood 2008, I | 2: 127.

15. Keating MJ, Flinn I, Jain V, Binet J-L, Hillmen P, Byrd JC, Albitar M, Brettman L, Santabarbara $P$, Wacker B, et al.: Therapeutic role of alemtuzumab (Campath-IH) in patients who have failed fludarabine: results of a large international study. Blood 2002, 99:3554-3561.

16. Fischer K, Stilgenbauer S, Schweighofer C, Busch R, Renschler J, Kiehl $M$, Balleisen L, Eckart MJ, Fink AM, Kilp J, et al.: Bendamustine in combination with rituximab (BR) for patients with relapsed chronic lymphocytic leukemia (CLL): A multicentre phase II trial of the German CLL Study Group (GCLLSG). Blood 2008, II 2: 128

17. Lin TS, Heerema NA, Lozanski G, Fischer B, Blum KA, Andritsos LA, Jones JA, Flynn JM, Moran ME, Mitchell SM, et al.: Flavopiridol (Alvocidib) induces durable responses in relapsed chronic lymphocytic leukemia (CLL) patients with high-risk cytogenetic abnormalities. Blood 2008, I I 2:23-24.

18. Osterborg A, Kipps TJ, Mayer J, Stilgenbauer S, Williams CD, Hellmen A, Robak T, Furman RR, Hillmen P, Trneny M, et al.: Ofatumumab (HuMax-CD20), a novel CD20 monoclonal antibody, is an active treatment for patients with CLL refractory to both fludarabine and alemtuzumab or bulky fludarabine-refractory disease: Results from the planned interim analysis of an international pivotal trial. Blood 2008, I | 2:126-127.

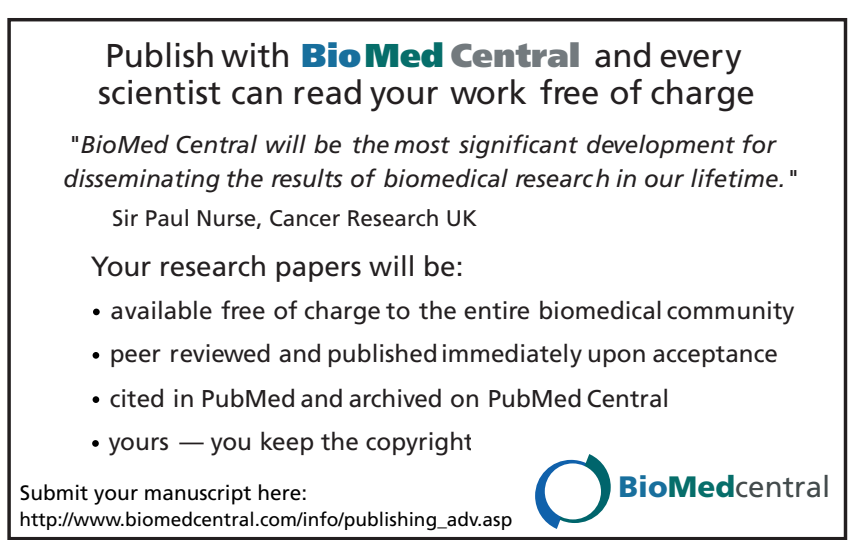

